\title{
Crops For the Future (CFF): an overview of research efforts in the adoption of underutilised species
}

\author{
Peter J. Gregory ${ }^{1,2}$ (D) Sean Mayes ${ }^{1,3} \cdot$ Chai Hui Hui $^{1}$. Ebrahim Jahanshiri ${ }^{1}$ - Advina Julkifle ${ }^{1} \cdot$ Giva Kuppusamy $^{1}$. \\ Ho Wai Kuan ${ }^{1,4} \cdot \operatorname{Tan}$ Xin Lin $^{1}$ · Festo Massawe ${ }^{4}$ - T. A. S. T. M. Suhairi ${ }^{1}$ - Sayed N. Azam-Ali ${ }^{1}$
}

Received: 11 September 2018 / Accepted: 30 April 2019 / Published online: 27 June 2019

(c) The Author(s) 2019

\begin{abstract}
Main conclusion Crops For the Future (CFF), as an entity, has established a broad range of research activities to promote the improvement and adoption of currently underutilised crops.
\end{abstract}

\begin{abstract}
This paper summarises selected research activities at Crops For the Future (CFF) in pursuit of its mission 'to develop solutions for diversifying future agriculture using underutilised crops'. CFF is a research company focussed on the improvement of underutilised crops, so that they might be grown and consumed more widely with benefits to human food and nutritional security; its founding guarantors were the Government of Malaysia and the University of Nottingham. From its base in Malaysia, it engages in research around the world with a focus on species and system diversification. CFF has adopted a food system approach that adds value by delivering prototype food, feed and knowledge products. Bambara groundnut (Vigna subterranea) was adopted as an exemplar crop around which to develop CFF's food system approach with emphasis on the short-day photoperiod requirement for pod-filling and the hard-to-cook trait. Selective breeding has allowed the development of lines that are less susceptible to photoperiod but also provided a range of tools and approaches that are now being exploited in other crops such as winged bean (Psophocarpus tetragonolobus), amaranth (Amaranthus spp.), moringa (Moringa oleifera) and proso (Panicum miliaceum) and foxtail (Setaria italica) millets. CFF has developed and tested new food products and demonstrated that several crops can be used as feed for black soldier fly which can, in turn, be used to feed fish thereby reducing the need for fishmeal. Information about underutilised crops is widely dispersed; so, a major effort has been made to develop a knowledge base that can be interrogated and used to answer practical questions about potential exploitation of plant and nutritional characteristics. Future research will build on the success with Bambara groundnut and include topics such as urban agriculture, rural development and diversification, and the development of novel foods.
\end{abstract}

\section{CFF's remit and research objectives}

Peter J. Gregory

p.j.gregory@ reading.ac.k

1 Crops for the Future, Jalan Broga, 43500 Semenyih, Selangor Darul Ehsan, Malaysia

2 School of Agriculture, Policy and Development, University of Reading, Earley Gate, Reading RG6 6AR, UK

3 School of Biosciences, University of Nottingham, Sutton Bonington, Loughborough LE12 5RD, UK

4 School of Biosciences, University of Nottingham Malaysia Campus, Jalan Broga, 43500 Semenyih, Selangor Darul Ehsan, Malaysia
The Research Centre of Crops For the Future (CFF), located at Seminyeh, Malaysia and comprising laboratories, offices and a field research centre, was launched in 2011 as the world's only centre with an exclusive remit to work on underutilised crops. The Centre's vision is to be recognised as a world leader producing excellent, innovative research on underutilised crops that is development focussed, and with a mission to develop solutions to diversify agriculture using underutilised crops to improve food and nutritional security and livelihoods especially of the poor. Funding for its research activities comes from its two funding guarantors (the Government of Malaysia and the University of Nottingham) and from competitive contracts obtained from a variety of sources including the UK Newton Fund, the EU, FAO and 
the YSY Foundation. CFF is a member of the Association of International Research and Development Centers for Agriculture (AIRCA) and several other international partnerships, and has collaborative projects with many scientists in countries including Ghana, Indonesia, Nigeria, South Africa, Vietnam and Zimbabwe.

Underutilised crops are frequently important local sources of food but have not been widely adopted elsewhere for a variety of reasons. Often, they are grown in marginal environments that are too harsh for staple cereal crops such as maize, rice and wheat and also cultivated in mixed agricultural/garden systems at a landscape rather than a field level. The need for a Centre such as CFF arises for several reasons but not least because human food systems are currently dominated by four crops-rice, wheat, maize and soybean - of which the three cereals provide over $50 \%$ of plant-based human food (IPES-Food 2016). In a warming world with more extreme weather, reliance on such a limited number of crops poses major challenges to food and nutritional security (Kahane et al. 2013; Weyant et al. 2018). Furthermore, existing deficiencies of key vitamins and minerals pose a serious constraint to human health and economic development (GLOPAN 2016). While the four dominant crops might be biofortified to produce these nutritional components, the complementary approach of a diverse diet comprising fruits, vegetables, grains and nuts also leads to enhanced human nutrition and health (GLOPAN 2016; Gregory et al. 2017; Jones 2017). Although the relationship between agricultural diversity and dietary diversity is not linear (possibly an inverse U shape), low levels of on-farm crop diversity for subsistence farmers typically lead to poor diets, so that encouragement to grow multiple crops can positively enhance human diets (Jones 2017).

The aim of CFF's research is to enhance the development and production of currently underutilised crops, by delivering evidence, knowledge and prototypes of value-added products for public and commercial good. In furtherance of this aim, CFF is responsive to societal demands for more sustainable and nutritious food systems and actively seeks collaboration and partnerships. Research activity is focussed on species and system diversification together with knowledge exchange and dissemination. To these ends, the research objectives are to: (1) use genetic diversity and genomics to develop viable phenotypes and genotypes of currently underutilised crop species for production in a range of cropping systems; (2) integrate knowledge of crop type, diversity and agronomy to develop practices to optimise crop performance, quality and resource use efficiency in specific cropping systems; (3) use a food system approach to identify the major factors influencing nutritional, and other desirable qualities, of underutilised crop species along the value chain, and develop innovative food and non-food products for public and commercial good; (4) develop an evidence base on underutilised crops to assess their potential contributions to the bioeconomy and food and nutritional security in current and future climates; and (5) communicate the evidence and opportunities offered by currently underutilised crops to benefit societies worldwide. Figure 1 summarises CFF research activities as a food system approach that adds value by delivering prototype food, feed and knowledge products. In furtherance of these objectives, CFF employs diverse skills including geneticists, crop physiologists, nutritionists, aquaculturists, food scientists, computer programmers, soil scientists, social scientists and information specialists.

Recent successes in furthering CFF's research objectives include publication of draft genomes of five African underutilised crops in partnership with the African Orphan Crops Consortium and others (Chang et al. 2018), proof of
Fig. 1 CFF's research strategy involves four themes and three cross-cutting threads to deliver a food systems approach

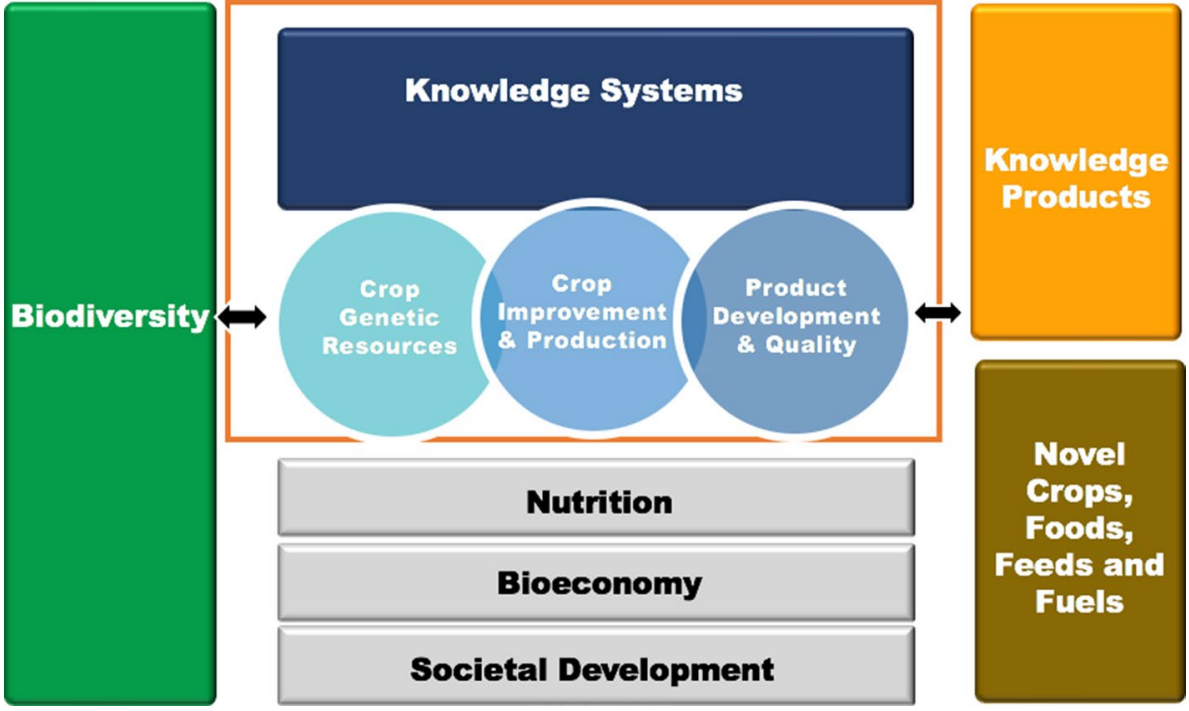


concept that black soldier flies fed with underutilised crops can be used to partially replace fishmeal in fish production (Katya et al. 2017), and the development of databases that contain phenological, agronomic and nutritional information about many underutilised crops (Marahaini et al. 2019). The purpose of this paper is to: (1) introduce CFF and its research ambition to an international audience; (2) describe some of its current research activities and priorities; and (3) highlight some emerging research priorities.

\section{CFF current research priorities}

\section{Improvement of Bambara groundnut}

At its inception, CFF decided to work on a small number of crops using Bambara groundnut (Vigna subterranea) as a case study for developing improved genotypes from landraces and wild relatives and accommodating them into extant cropping and food systems (http://www.bamyi eld.org). It is an African legume (Hepper 1963) that is favoured for food security in sub-Saharan Africa and prized for its drought tolerance (Linnemann and AzamAli 1993; Hillocks et al. 2012; Adzawla et al. 2016a, b) with the potential to contribute to climate change readiness (Mabhaudhi et al. 2018). In symbiotic partnership with rhizobia, it is able fix atmospheric nitrogen and its crop physiology (and initial genetics) was extensively studied in a series of research grants led by the University of Nottingham with international partners from the late 1990s (e.g. BAMLINK-EU FP6 INCO-DEV 2006-2011). Two traits were identified as limiting the more widespread adoption of the crop, namely the short-day photoperiod requirement for pod-filling (a very rare effect of day length in crops; Linnemann et al. 1995; Jørgensen et al. 2009; Berchie et al. 2013; Kendabie et al. 2015) and the hard-to-cook phenomenon (Shehata 1992; Mubaiwa et al. 2017), which is common in pulse legumes. The first restricts the range of latitudes/timing of planting of the crop, while the latter is a problem because of the fuel demands it places on poor households. With partners, CFF is currently investigating both phenomena (see Mayes et al. 2019 for details) and has already bred a source of lower photoperiod sensitivity into a wide range of lines through controlled crossing. These are being tested in several African countries and this will soon be extended to Northern Africa and Southern Europe. Mubaiwa et al. (2017) compared the cookability of Bambara groundnut in comparison with other legumes and found it to be similar to soybean at $3.6 \mathrm{~h}$. Preliminary work suggests that QTL exist for imbibition time in a controlled cross, but are unrelated to testa colour (suggested previously to be related to cookability) but further studies are underway (Mayes et al. 2019). Multiple approaches have been pursued to explore the hard-to-cook property including evaluation of simple processing techniques, combined with using the controlled genetic populations to understand the genetic control of components of the phenomenon. Any changes at the genetic level, through conventional breeding, will also be assessed for potentially negative consequences such as increased susceptibility to storage weevil.

In Malaysia, genotypes have been grown and selected at the CFF field station (Musa et al. 2016) in Selangor state for over 4 years and, more recently, in Kedah and Terengganu states. Through this series of assessments, lines have been identified and bred which work well within this humid tropical environment. Through an International Treaty for Plant Genetic Resources for Food and Agriculture grant (http://www.fao.org/plant-treaty/areas-of-work/ benefit-sharing-fund/projects-funded/bsf-third-cycle/en/), a common set of genotypes has been trialed with partners in Nigeria, Ghana and Indonesia and large collections of single genotype lines are being introduced to farmers in those countries for farmer selection as the basis for participatory breeding. Our current approach is to work with in-country partners, so that farmers are directly involved in the evaluation steps. Initial survey data from Ghana (Adzawla et al. 2016a, b), Nigeria (Olayide et al. 2018) and Indonesia (manuscript in preparation) have informed breeding targets, and introduction of a range of lines from the Association Panel that meet those farmer criteria is the next step. This may lead to direct adoption of lines or identify those lines containing a farmer-desired trait for future introgression into local lines. It is also important to recognise that the wide range of environments in which Bambara groundnut is grown means that the level and nature of drought tolerance present in different accessions will differ. This potentially means that for the harshest environments, it may be possible to combine different components into single cultivars or even cultivar mixes, analogous to landraces.

The material developed also allows fundamental genetic research in the form of controlled crosses segregating for traits of value (Ahmad et al. 2016; Chai et al. 2016) or an association genetics panel for genetic diversity (Molosiwa et al. 2015) and trait dissection (Bonthala et al. 2016; Chai et al. 2017; Ho et al. 2017; Khan et al. 2017). A dedicated breeding programme will begin in the immediate future with the aim of registering improved material in African countries, working with small and ethical seed companies as partners (Aliyu et al. 2014, 2016). The recent developments in next generation sequencing are also benefiting the crop, as genotyping-by-sequencing (GBS; https://www. diversityarrays.com/) has already allowed comparison of over 500 genotype lines of the crop and assessments of their genetic diversity. Perhaps more importantly, collaboration 
with the African Orphan Crops Consortium (AOCC; http:// www.africanorphancrops.org; Ho et al. 2016; Dawson et al. 2018) has led to Bambara groundnut being one of the first five assembly releases from their programme for 101 orphan African crop genomes (Chang et al. 2018). The 100 lines for resequencing by AOCC were a community call coordinated through the community crop web-site 'BamNetwork' (http:// www.bambaragroundnut.org).

The strategy of the AOCC effort is to generate high-density illumina short-read data for the selected genomes. For Bambara groundnut, the initial data suggest good coverage of the coding regions (BUSCO 92.5\%; ref) and we have also used existing genetic maps in Bambara groundnut (sequence tags associated with DArT Seq) to place scaffolds onto the genetic map. However, the absence of long read sequence data (such as Nanopore or PacBio) currently means that pseudochromosomes are not available. We intend to address this in 2019 through generating nanopore sequence for the original genotype. In the absence of a complete and finished sequence, we are beginning to place scaffolds onto related and complete genomes (particularly cowpea and common bean) to facilitate both Association analysis and breeding. Re-sequencing data have yet to be released by ICRAF, but combined with the complete genome, we would expect that one of the first developments could be a dedicated SNP chip, alongside initial analysis of the forces which have selected for differences between different origins of Bambara groundnut.

Genetic improvement and production is, though, only one consideration. Through Government of Malaysia funding, the processing machinery needed to take the newly harvested pods and convert the seeds into flour at a medium level (100 kg per day) is being developed (BAMPRO-MOSTI funded; Government of Malaysia). Prototypes are being developed for both planting and harvesting machinery, to facilitate large-scale production. The nutritional (and antinutritional), physical and chemical properties of the crop are being evaluated to understand better how to develop food products and food ingredients, to identify where markets could be developed or where there is the option for replacing a major crop ingredient with one from Bambara groundnut (Halimi et al. 2019). These will depend on genotype and will certainly be influenced by the growing environment and soil; so, an assessment in the target environment for nutritional components and their stability is important.

Another important area in the adoption of underutilised crops is that of policies at country, regional and continental levels. Without supportive policies, it will be more difficult to complete the Food System, although high-value components (such as ingredients) may still allow market placement and development.
Investigation of further underutilised crops (winged bean, moringa, proso and foxtail millets, amaranth)

While Bambara groundnut is an exemplar, it is critical to CFF's mission that there is translation of practice and knowledge from that crop to other crops. Approaches used to develop Bambara groundnut, and to translate information from major and model plant species, can be adapted and applied to other underutilised crops. CFF is currently working on the translation to a number of other underutilised/minor species. Winged Bean (Psophocarpus tetragonolobus) is a vining tropical pulse legume with a seed composition close to soybean. We are working with researchers, seed companies and academia to develop and characterise this crop further and currently have around 400 accessions, with around 200 from the East-West Seeds breeding programme in the Philippines (Wong et al. 2017; Tanzi et al. 2019a, b). We also have a first draft of the genome sequence (Mayes, unpublished data). Controlled crosses have been made and the first two genetic maps are under construction. Moringa oleifera (recently sequenced by AOCC) has high protein content in the leaves and could be a useful component of the diet in countries where animal protein is scarce or is not acceptable. An initial collection from around Malaysia will be combined with material of known origin to assess from where the Malaysian material originated and how broad it is genetically.

A very extensive collection of around 150 Proso/ Broomcorn millet accessions (Panicum miliaceum) and 600 Foxtail millet accessions (Setaria italica) has been assembled by the McDonald Institute in Cambridge University whose primary interest is in crop domestication and spread (Hunt et al. 2018). The collections have been made available as part of collaborative work to evaluate their potential for future cropping systems to the University of Nottingham and partners. Both crops probably originate in China and are seen as being part of Chinese crop heritage. We are collaborating with Shanxi Agricultural University on Foxtail millet, where significant research progress is being made, and with researchers in Sri Lanka for proso millet. We have sent 150 lines of Foxtail millet for DArT Seq GBS analysis and have pilot work beginning to evaluate a number of traits in controlled glasshouses (drought, salt stress and root structure) on the same lines.

A collection of amaranths (focused on Amaranthus tricolor) is also being evaluated for diversity and drought tolerance, with collaborators including the University of Nottingham, John Moore's University Liverpool, University of Reading, East-West Seeds and the World Vegetable Centre in Taiwan. Genetic analysis has been through the use of GBS DArT Seq and the development of a limited number of SSR markers. A subset of the collection has also been evaluated for response to drought using a rainout 
shelter in Malaysia (as a first step) and we hope to work with East-West Seeds to extend this initial work through to field evaluation in Tanzania in the near future.

Progress in all of these crops requires a network approach ranging from fundamental research to directly working with farmer participatory selection. This approach has allowed progress in Bambara groundnut, and the lessons learned should facilitate faster progress in other underutilised crops.

\section{The food systems (CONNECT) approach}

CFF is committed to a food systems approach that tracks the properties of a food ingredient through its growth, storage, processing and inclusion into a food. In 2017, this was made a reality by bringing together many scientists into a single project (CONNECT) to follow the nutritional changes in crops of Bambara groundnut and moringa from production in the field, through harvesting, drying and processing to inclusion in noodles. The project aimed to provide results that will allow stakeholders to compare diversification options that include underutilised crops against current systems as well as the most suitable crops at any location (climate smart agriculture). It will also provide a mechanism to develop new nutritious food products and identify their potential market (dietary diversification). The plant materials and wheat-based noodles containing either $20 \%$ Bambara groundnut or $6 \%$ moringa leaf powder were analysed for proximate composition, major and minor minerals, and amino acids. The acceptability of the noodles to potential consumers was tested on an untrained panel comprising 86 participants.

It was noteworthy that moringa contained much higher concentrations of calcium, magnesium and manganese in its foliage than Bambara groundnut. As a consequence, a slight addition of moringa to the noodles significantly increased the calcium, magnesium and manganese concentrations together with selenium. Nevertheless, the inclusion of either moringa or Bambara groundnut into the noodles significantly improved fibre content and other minerals important for human nutrition including phosphorus, potassium and zinc compared to wheat noodles. Consumer acceptance of the noodles was between neutral and moderate liking, except for the odour of noodles to which moringa leaf powder had been added which was mild dislike.

\section{Developing new recipes and forgotten foods}

One reason that underutilised crops remain underutilised is because people are unsure of how they can be used as food. CFF has adopted two strategies to deal with this. First, CFF has employed a food development specialist who has researched how the crop products might be combined with other ingredients to give acceptable food. Figure 2 shows some examples of the foods that have been developed which include biscotti (Bambara groundnut), soup (moringa), noodles (Bambara groundnut) and a range of snacks. Second, CFF has initiated the Forgotten Foods Network (http://www. forgottenfoodsnetwork.org/) which brings together recipes from individuals and will be expanded to cover several countries. Many of these foods are in danger of disappearing for reasons that include the long time necessary to prepare the food, demographic shift accompanied by dietary changes, limited supply and/or demand for the forgotten foods, lack of advanced postharvest and processing technologies, and the advanced age of those who remember preparing these foods in the past.

\section{Underutilised crops for aquaculture feed and energy}

Most fisheries around the world are unsustainable although the demand for fish and seafoods continues to rise. Aquaculture has expanded to fill some of the demand, but many current production facilities require large amounts of fishmeal to feed the fish. CFF has demonstrated, in principle, that fishmeal can be replaced by insectmeal fed on currently underutilised crops thereby producing farmed fish for humans, conserving wildfish stocks and utilising biomass that cannot be used as human food.

CFF has established rearing protocols for producing Black Soldier Fly (BSF) utilising housing units that allow access to larvae throughout their growing cycle. Proximate analysis of commercially available fish feeds was used to formulate fish feeds incorporating varying percentages of BSF insect meal. The nutrient composition of candidate underutilised crops (Bambara groundnut, moringa and sesbania (Sesbania grandiflora) to be fed to the BSF larvae was analysed and shown to meet key nutritional requirement of fish. Leaves have been found to give the best results; these are ground and turned into a moist sludge for use as a feed substrate. Early trials indicated that sesbania gave the best results and, unlike Bambara groundnut, was available as a continuous supply from the perennial bushes. Analysis of the amino acid composition of BSF larval meal showed that essential amino acid concentration was slightly lower than that of fish meal but, when compared with other potential fish feed constituents, such as soybean, the BSF meal compared favourably. Some of the essential amino acids equalled, or exceeded (e.g. lysine), the composition of soyabean per unit of protein.

A feeding trial with Lates calcarifer (Barramudi, South East Asia Sea Bass) was undertaken over 8 weeks and showed that fish meal could be replaced with BSF meal to a level of $50 \%$ without any deleterious effects on growth rates or survivability (Katya et al. 2017). At 75\% replacement, growth rate was reduced by approximately $25 \%$ (Katya et al. 

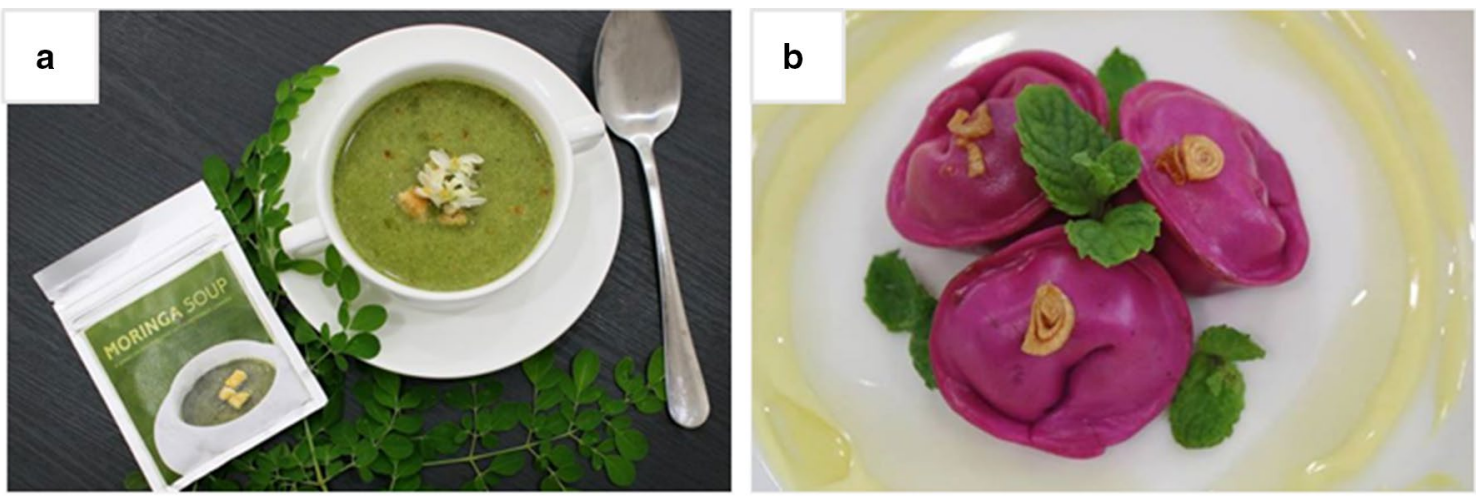

C

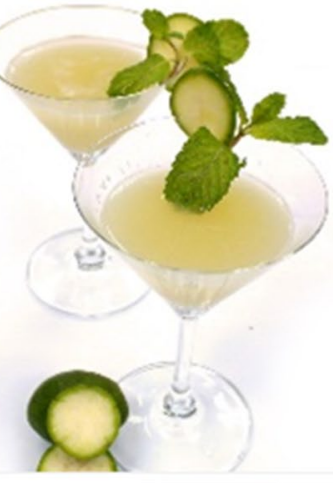

d
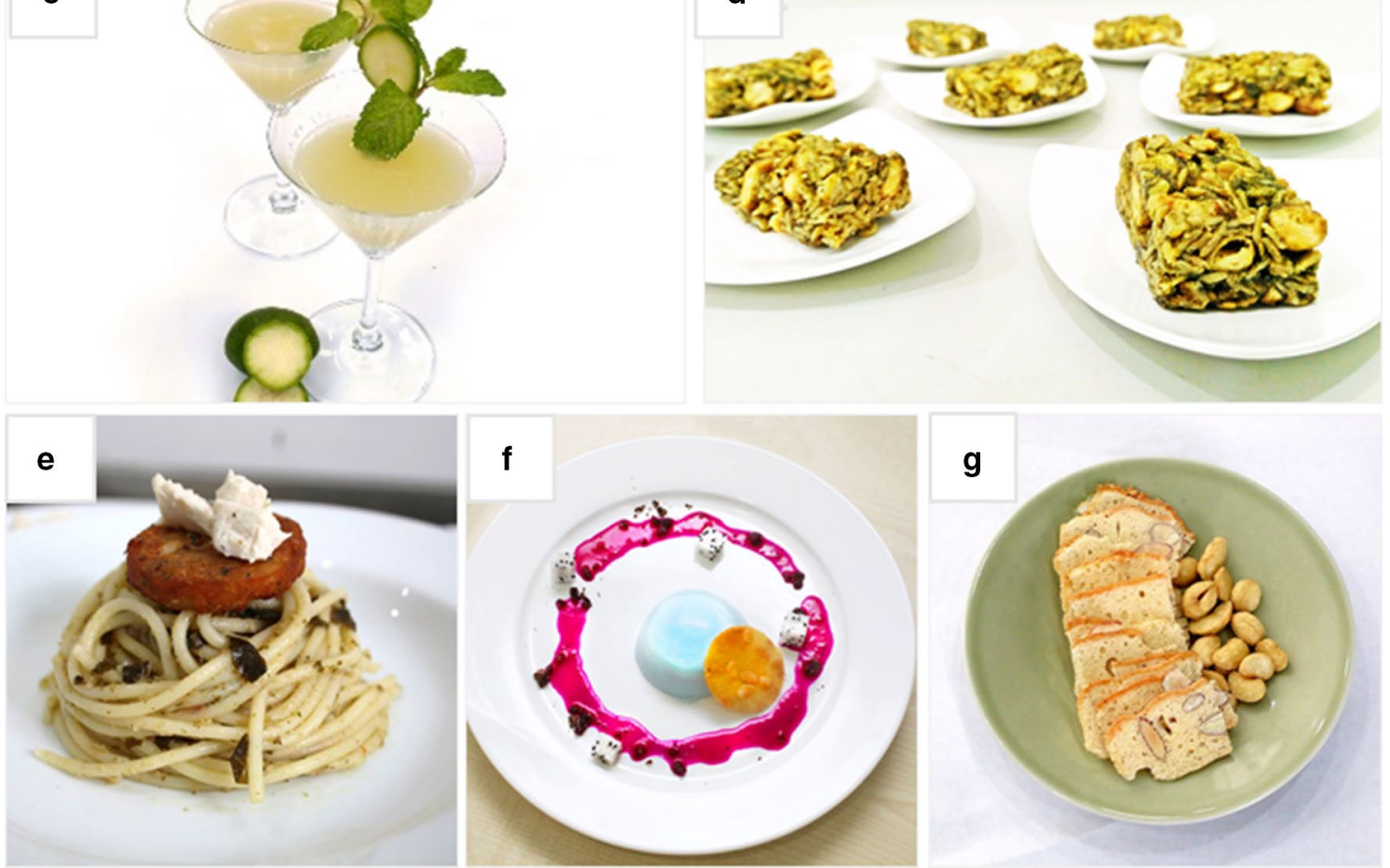

Fig. 2 Food and beverage products developed at CFF using moringa, Bambara groundnut, dragon fruit and kedondong fruit. a Moringa instant soup, b Dragon fruit tortellini with beans and greens, $\mathbf{c}$
Kedondong ginger ale, d Moringa and Bambara groundnut granola bar, e Bambara groundnut noodle, f Bambara groundnut panacotta and $\mathbf{g}$ Bambara groundnut biscotti

Table 1 The composition of Black Soldier Fly (Hermetia illucens) larvae fed with different feedstocks

\begin{tabular}{lllllrr}
\hline Sample & Moisture (\%) & Ash $(\%)$ & Protein $(\%)$ & Fat $(\%)$ & CHO (\%) & Crude fibre $(\%)$ \\
\hline Palm kernel cake (PKC) 100\% & 8.78 & 9.68 & 53.98 & 17.00 & 10.56 & 7.84 \\
Moringa 25\% + PKC 75\% & 6.34 & 10.83 & $51.39^{*}$ & 14.63 & 16.82 & 10.82 \\
Moringa 50\%+PKC 50\% & 5.49 & 10.88 & 55.76 & 15.99 & 11.9 & 8.23 \\
Sesbania 25\%+PKC 75\% & 7.48 & 10.53 & 53.01 & 16.90 & 12.09 & 8.65 \\
Sesbania 50\%+PKC 50\% & 6.16 & 11.98 & 50.72 & 15.37 & 15.79 & 10.66 \\
Coconut 25\%+PKC 75\% & 6.13 & 8.16 & $48.21^{*}$ & 20.99 & 16.54 & 10.44 \\
Coconut 50\%+PKC 50\% & 6.29 & 6.57 & $41.56^{*}$ & 35.74 & 9.84 & 6.81 \\
\hline
\end{tabular}

Values followed by * are significantly $(p>0.05)$ than the PKC value 
2017). Fish fed $100 \%$ insect meal showed markedly reduced growth rates (reduced by approximately three-quarters) but survival was not significantly below that seen in the control fish (Katya et al. 2017).

More recently, CFF research has focused on improving the nutritional value of larval meal as a component of nutritionally optimised diets for Tilapia production. BSF larvae were fed for a period of 14 days with a diet comprising palm kernel cake that had been supplemented with either $25 \%$ or $50 \%$ of each of M. oleifera, S. grandiflora and Cocus nucifera (coconut). The highest protein concentration was obtained when $50 \%$ moringa was fed to the larvae, although this was not significantly higher than the palm kernel cake control (Table 1). Additions of coconut significantly reduced the protein concentration compared to the control but increased the fat concentration of the larvae. This finding is important because at a commercial scale, defatting BSF meal to extract the protein involves a huge energy input. BSF with less than $20 \%$ lipid will not require defatting.

\section{Knowledge systems to promote the adoption of underutilised crops}

Knowledge on underutilised crops is widely distributed around the world but much of it is held in fragmented form. CFF has developed a Global Knowledge Base that brings together data from different facets of underutilised crops including geographical, climatic, edaphic, agroecological, nutritional and biological information in forms that can be used to provide initial answers to specific questions.
An example of how the data might be used is research that sought to determine whether Bambara groundnut is a viable crop for Malaysia that might reduce the dependency on imported soybean and maize as sources of protein and carbohydrate. Using available climatic and edaphic data (mean monthly temperature and rainfall and soil classes and soil $\mathrm{pH}$ from reconnaissance surveys), the suitability of Bambara groundnut was assessed relative to maize throughout Malaysia. Considering general species niche requirements, Bambara groundnut was at minimum $89 \%$ climatically suited compared to only $62 \%$ for maize when both started growth in June-which is not the ideal sowing time for Bambara groundnut. On acidic soils $(\mathrm{pH}<4.5)$, Bambara groundnut was suitable on $59 \%$ of all soils in Malaysia compared to only $23 \%$ for maize (Fig. 3). Further analysis of Bambara groundnut's suitability in Peninsular Malaysia using published land-use data showed that of the total land suitable for agriculture, $24.56 \%\left(31,484 \mathrm{~km}^{2}\right)$ is suitable and $72.36 \%\left(95,086.64 \mathrm{~km}^{2}\right)$ is moderately suitable (Suhairi et al. 2018).

A variety of other similar questions on land-crop suitability can be answered with the development of knowledge prototypes. One example of this is SelectCrop, an Automatic Land Suitability Assessment system for underutilised crops (http://www.cropbase.org). The SelectCrop model shortlists crops based on climate, soil and land-use type at any location. Tests of the SelectCrop model against available accession coordinates from four crops obtained from Genesys (the Global Gateway to Genetic Resources) showed that the combined model of climate-soil suitability can correctly

a
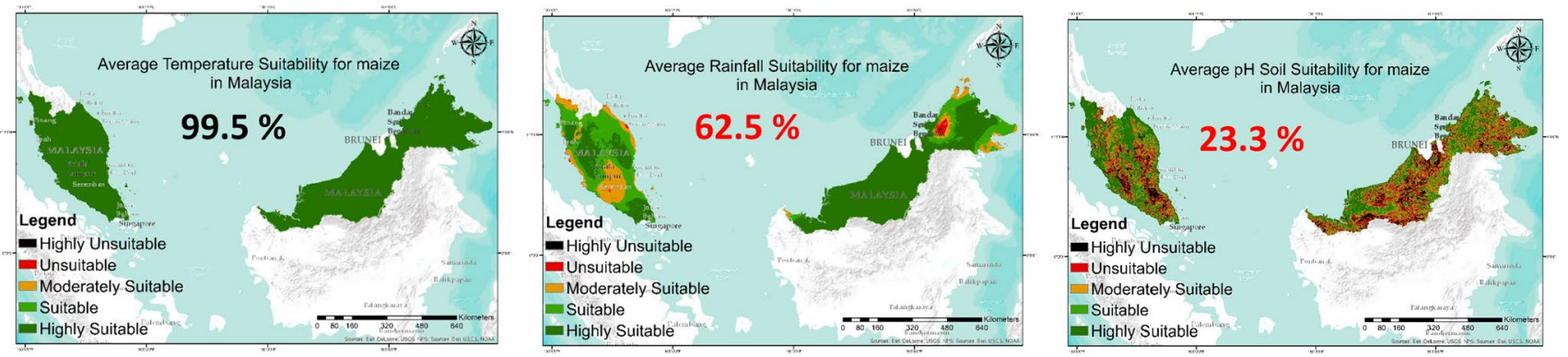

b
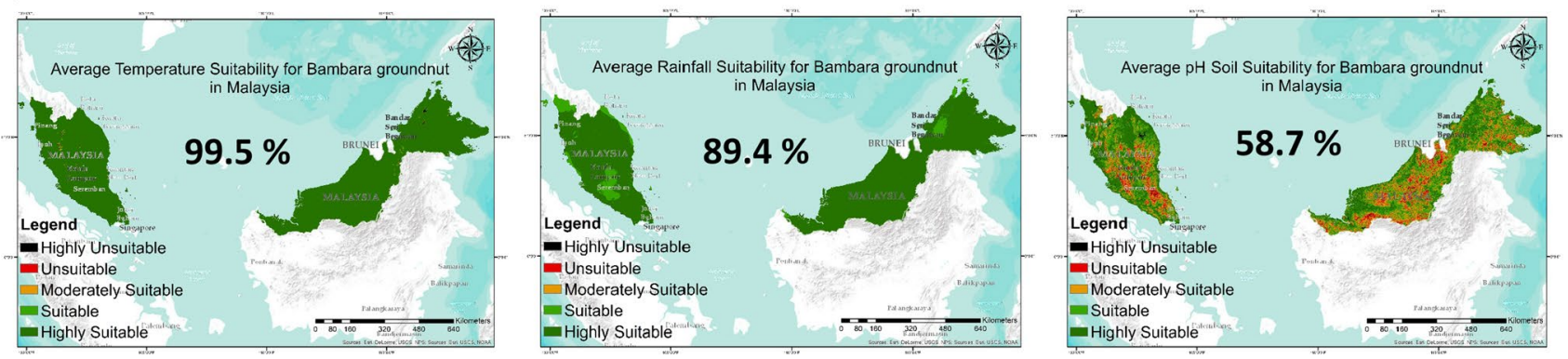

Fig. 3 Preliminary suitability comparison for $\mathbf{a}$ maize and $\mathbf{b}$ Bambara groundnut using available data 
predict the suitability of pigeonpea (Cajanus cajan, with an average suitability of 70\%) and pearl millet (Pennisetum glaucum, with an average suitability of $60 \%$ ) assuming all accessions were collected from rain-fed fields; the accuracy of these predictions is the subject of on-going work. Using the same integrated approach for organised data and automated analysis, CFF is able to quickly identify alternative/ complementary crops and cropping systems that might be suitable for an area; value chains can also be estimated using related economic and market data.

\section{Emerging research priorities}

\section{Urban agriculture}

One element of urban agriculture that is coming to the fore is that of using roofs to support vertical farming systems. By 2050, 2.5 billion more people will live in cities and of these, $90 \%$ will be in Asia and Africa. In Malaysia alone the urban population will grow to $85 \%$ of the total population by 2050, and 13 million people will live in Kuala Lumpur. This will bring huge societal and economic challenges, not just in the provision of services but also for community harmony and wellbeing. Many city dwellers have migrated from rural areas with access to space, food and culture, to confined urban spaces and fractured communities. Their knowledge of crops and farming systems is not now utilised, and they rely on purchased, often imported, foods.

With partners in various 'Green City' initiatives, CFF will explore the potential for using urban rooftops to produce healthy, locally sourced food, grown by and for the urban young and elderly communities. We will develop approaches linking their skills and knowledge of growing fresh produce with new technologies that will improve nutrition, promote active lifestyles, and enhance well-being. CFF has recently signed a contract with a local entrepreneur to produce vegetables in hydroponic units stacked vertically on its rooftops. This is the first stage in researching bespoke irrigation and fertiliser treatments that optimise yield and nutritional properties of vegetables and fruits.

\section{Rural development in Kedah, Malaysia}

Kedah is the eighth largest state in Malaysia. Of the 518,000 hectares of land in the state used for agriculture, most is utilised for rice cultivation $(112,000 \mathrm{ha})$, rubber (108,000 ha) and oil palm (84,000 ha). Kedah is known as 'the Rice Bowl' of Malaysia, accounting for approximately $40 \%$ of national rice production but the increasing frequency of natural disasters and changing weather patterns are affecting crop productivity, threatening the livelihoods of small-scale farmers and deterring investment in Kedah.

Ageing farmers, small plots and a low density of irrigation infrastructure, coupled with a lack of capital to strengthen mechanisation or invest in farm inputs, mean that many Kedah farmers languish at the bottom of the productivity scale. Falling farm incomes due to impacts of climate change and other impacts faced by farmers on unstable rice production increase Malaysia's dependence on imported rice and cause a further burden on the livelihoods of farmers.

There is an urgent need to transform Kedah's agriculture beyond the sustenance of its population to a more diverse and sustainable system for its nourishment and health. For this, Kedah needs to diversify its agricultural systems to include a range of crops that can produce nutritious and marketable products that are desirable to endusers and can be cultivated in Kedah's increasingly vulnerable climates and soils.

$\mathrm{CFF}$ is working with partners to develop agricultural diversification opportunities for climate-vulnerable states such as Kedah. Its objective is to provide new livelihood options for rural communities through innovations that support diversified and integrated agricultural and aquaculture value chains. However, this requires new approaches that build on the traditional strengths of its paddy and plantations with novel business opportunities that use underutilised crops to provide value addition through diversification beyond monocultures. These include initiatives that link agriculture and aquaculture into integrated and diversified systems which are economically viable and resilient to changing environments.

\section{Concluding remarks}

In the last 5 years CFF has established itself as a centre for innovative research on underutilised crops in a range of food systems. In the next phase of its development, it will collaborate widely with other organisations to promote its agenda of agricultural diversification with benefits to both human health and the wider environment. In a short time, it has produced the disruptive technology associated with feeding black soldier fly in aquaculture systems (Katya et al. 2017), developed a freely available knowledge base containing details of 2300 underutilised crops (http://www. cropbase.org), and its genetic research will shortly publish the gene sequence for winged bean to add to the sequences already published (Chang et al. 2018). CFF will continue to promote the Global Action Plan for Agricultural Diversification (GAPAD) through its participation in the AIRCA consortium, and work with a range of partners to mainstream nutrition in agricultural diversification initiatives. 
Author contribution statement PJG was the coordinating author for the written contributions of all other authors.

Open Access This article is distributed under the terms of the Creative Commons Attribution 4.0 International License (http://creativeco mmons.org/licenses/by/4.0/), which permits unrestricted use, distribution, and reproduction in any medium, provided you give appropriate credit to the original author(s) and the source, provide a link to the Creative Commons license, and indicate if changes were made.

\section{References}

Ahmad NS, Redjeki ES, Ho WK, Aliyu S, Mayes K, Massawe F, Kilian A, Mayes S (2016) Construction of a genetic linkage map and QTL analysis in bambara groundnut (Vigna subterranea (L.) Verdc.). Genome. https://doi.org/10.1139/gen-2015-0153

Adzawla W, Donkoh SA, Nyarko G, O'Reilly PJ, Olayide O, Mayes S, Feldman AB, Azman Halimi R (2016a) Adoption of Bambara groundnut production and its effects on farmers' welfare in Northern Ghana. Afr J Agric Res 11:583-594

Adzawla W, Donkoh SA, Nyarko G, O'Reilly P, Mayes S (2016b) Use patterns and perceptions about the attributes of Bambara groundnut (Vigna subterranea (L.) Verdc.) in Northern Ghana. Ghana J Sci Technol Dev 4:56-71

Aliyu S, Massawe F, Mayes S (2014) Beyond landraces: developing improved germplasm resources for underutilized species-a case for Bambara groundnut. Biotechnol Genet Eng Rev 30:127-141

Aliyu S, Massawe F, Mayes S (2016) Genetic diversity and population structure of Bambara groundnut (Vigna subterranea (L.) Verdc.): synopsis of the past two decades of analysis and implications for crop improvement programmes. Genet Resour Crop Evol 63:925-943

Berchie JN, Amelie G, McClymont S, Raizada M, Adu-Dapaah H, Sarkodie-Addo J (2013) Performance of 13 Bambara groundnut (Vigna subterranea (L.) Verdc.) landraces under $12 \mathrm{H}$ and $14 \mathrm{H}$ photoperiod. J Agron 12:20-28

Bonthala VS, Mayes K, Moreton J, Blythe M, Wright V, May ST, Massawe F, Mayes S, Twycross J (2016) Identification of gene modules associated with low temperature response in Bambara groundnut by network-based analysis. PLoS One 11:e0148771

Chai HH, Massawe F, Mayes S (2016) Effects of mild drought stress on the morpho-physiological characteristics of a bambara groundnut segregating population. Euphytica 208:225-236

Chai HH, Ho WK, Graham N, May S, Massawe F, Mayes S (2017) A cross-species gene expression marker-based genetic map and QTL analysis in Bambara groundnut. Genes 8:8-84. https://doi. org/10.3390/genes 8020084

Chang Y, Liu H, Liu M, Liu M, Liao X, Sahu SK, Fu Y, Song B, Cheng S, Kariba R, Muthemba S, Hendre PS, Mayes S, Ho WK, Yssel AEJ, Kendabie P, Wang S, Li L, Muchugi A, Jamnadass R, Lu H, Peng S, van Deynze A, Simons A, Yana-Shapiro H, van de Peer Y, Xu H, Yang H, Wang J, Liu X (2018) The draft genome of five agriculturally important African orphan crops. GigaScience 8:1-16

Dawson IK, Hendre P, Powell W et al (2018) Supporting human nutrition in Africa through the integration of new and orphan crops into food systems. Working paper 276 World Agroforestry Centre

GLOPAN (2016) Food systems and diets: Facing the challenges of the 21st century. Global Panel on Agriculture and Food Systems for Nutrition, London
Gregory PJ, Azam-Ali SN, Azam-Ali S (2017) Crop diversity for human nutrition and health benefits. World Agriculture, p 1720

Halimi RA, Barkla B, Mayes S, King G (2019) The potential of the underutilized pulse bambara groundnut (Vigna subterranea (L.) Verdc.) for nutritional food security. J Food Compos Anal 77:47-59

Hepper FH (1963) Plants of the 1957-58 West African expedition: II. the bambara groundnut (Voandzeia subterranea) and Kersting's groundnut (Kerstingiella geocarpa) wild in West Africa. Kew Bull 16:395-407

Hillocks RJ, Bennett C, Mponda OM (2012) Bambara nut: a review of utilisation, market potential and crop improvement. African Crop Sci J 20:1-16

Ho WK, Muchugi A, Muthemba S, Kariba R, Mavenkeni BO, Hendre P, Song B, Van Deynze A, Massawe F, Mayes S (2016) Use of microsatellite markers for the assessment of bambara groundnut breeding system and varietal purity before genome sequencing. Genome 59:427-431

Ho WK, Chai HH, Kendabie P, Ahmad NS, Jani J, Massawe F, Kilian A, Mayes S (2017) Integrating genetic maps in bambara groundnut [Vigna subterranea (L.) Verdc.] and their syntenic relationships among closely related legumes. BMC Genom 1:192

Hunt HV, Rudzinski A, Jiang H, Wang R, Thomas MG, Jones MK (2018) Genetic evidence for a western Chinese origin of broomcorn millet (Panicum miliaceum). Holocene 28:1968-1978

IPES-Food (2016) From uniformity to diversity: a paradigm shift from industrial agriculture to diversified agroecological systems. In: International panel of experts on sustainable food systems

Jones AD (2017) Critical review of the emerging research evidence on agricultural biodiversity, diet diversity, and nutritional status in low- and middle-income countries. Nutr Rev 75:769-782

Jørgensen ST, Aubanton M, Harmonic C, Dieryck C, Jacobsen SP, Simonsen HL, Ntundu WH, Stadler F, Basu S, Christiansen JL (2009) Identification of photoperiod neutral lines of bambara groundnut (Vigna subterranea) from Tanzania. IOP Conf Ser Earth Environ Sci 6:372

Kahane R, Hodgkin T, Jaenicke H, Hoogendoorn C, Hermann M, Keatinge JDH, d'Arros Hughes J, Padulosi S, Looney N (2013) Agrobiodiversity for food security, health and income. Agron Sustain Dev 33:671-693

Katya K, Borsra MZS, Ganesan D, Kuppusamy G, Herriman M, Salter A, Ali SA (2017) Efficacy of insect larval meal to replace fish meal in juvenile barramundi, Lates calcarifer reared in freshwater. Int Aquat Res 9:303-312

Kendabie P, Massawe F, Mayes S (2015) Developing genetic mapping resources from landrace-derived genotypes that differ for photoperiod sensitivity in Bambara groundnut (Vigna subterranea L.). Aspects Appl Biol Breed Plants Cope Future Clim Chan 124:49-56

Khan F, Chai HH, Ajmera I, Hodgman C, Mayes S, Lu C (2017) A transcriptomic comparison of two Bambara groundnut landraces under dehydration stress. Genes 8:121

Linnemann AR, Azam-Ali SN (1993) Bambara groundnut (Vigna subterranea (L.) Verdc.). In: Williams JT (ed) Underutilized crops series 2, vegetables and pulses. Chapman \& Hall, London, pp $13-58$

Linnemann A, Westphal E, Wessel M (1995) Photoperiod regulation of development and growth in bambara groundnut (Vigna subterranea). Field Crops Res 40:39-47

Mabhaudhi T, Chibarabada TP, Chimonyo VGP, Modi AT (2018) Modelling climate change impact: a case of bambara groundnut (Vigna subterranea). Phys Chem Earth. https://doi. org/10.1016/j.pce.2018.01.003 
Marahaini N, Jahanshiri E, Salama A, Tengku Adhwa Syaherah TMS (2019) Linking data across the value chain of underutilised crops-a multidisciplinary approach. Food Res 3:108-116

Mayes S, Ho WK, Chai HH, Gao X, Kundy AC, Kumbirai IM, Zahrulakmal M, Hahiree MKIM et al (2019) Bambara groundnutan exemplar underutilised legume for resilience under climate change. Planta (this issue)

Molosiwa OO, Aliyu S, Stadler F, Mayes K, Massawe F, Kilian A, Mayes S (2015) SSR marker development, genetic diversity and population structure analysis of Bambara groundnut (Vigna subterranea (L.) Verdc.) landraces. Genet Resour Crop Evol 62:1225-1243

Mubaiwa J, Fogliano V, Chidewe C, Linnemann AR (2017) Hardto-cook phenomenon in bambara groundnut (Vigna subterranea (L.) Verdc.) processing: options to improve its role in providing food security. Food Rev Int 33:167-194

Musa M, Al-Shareef I, Mayes S, Massawe F, Singh A (2016) Nitrogen fixation and $\mathrm{N}$-balance studies on Bambara groundnut (Vigna subterranea L. Verdc.) landraces grown on tropical acidic soils of Malaysia. Commun Soil Sci Plant Anal 47:533

Olayide OE et al (2018) Assessing socioeconomic factors influencing production and commercialization of bambara groundnut as an indigenous climate resilient crop in Nigeria. In: Leal Filho W (ed) Handbook of climate change resilience. Springer, Cham. https:// doi.org/10.1007/978-3-319-71025-9_158-1

Shehata AME-T (1992) Hard-to-cook phenomenon in legumes. Food Rev Int 8:191-221
Suhairi TASTM, Jahanshiri E, Nizar NMM (2018) Multicriteria land suitability assessment for growing underutilised crop, bambara groundnut in Peninsular Malaysia. IOP conference series: earth and environmental science, vol 169. IOP, Bristol, p 012044

Tanzi AS, Ho WK, Massawe F, Mayes S (2019a) Development and interaction between plant architecture and yield-related traits in winged bean (Psophocarpus tetragonolobus (L.) D.C.). Euphytica 22:22. https://doi.org/10.1007/s10681-019-2359-8

Tanzi ST, Eagleton GE, Ho WK, Wong QN, Mayes S, Massawe F (2019b) Winged bean (Psophocarpus tetragonolobus (L.) DC.) for food security: past research, and future improvement programmes. Planta (this issue)

Weyant C, Brandeau ML, Burke M, Lobell DB, Bendavid E, Basu $S$ (2018) Anticipated burden and mitigation of carbon-dioxideinduced nutritional deficiencies and related diseases: a simulation modeling study. PLOS Med 15(7):e1002586

Wong QN, Tanzi AS, Ho WK, Malla S, Blythe M, Karunaratne A, Massawe F, Mayes S (2017) Development of gene-based SSR markers in winged bean (Psophocarpus tetragonolobus (L.) DC.) for diversity assessment. Genes 8:100

Publisher's Note Springer Nature remains neutral with regard to jurisdictional claims in published maps and institutional affiliations. 